\title{
Efeito do genótipo e do sexo sobre a composição química e o perfil de ácidos graxos da carne de cordeiros
}

\author{
Marta Suely Madruga1, Waldinei Oliveira de Araújo², Wandrick Hauss de Sousa ${ }^{3}$, Marcílio \\ Fontes Cézar ${ }^{3}$, Mércia de Sousa Galvão ${ }^{1}$, Maria das Graças Gomes Cunha ${ }^{3}$

\footnotetext{
${ }^{1}$ Departamento de Tecnologia Química e de Alimentos, Universidade Federal da Paraiba (DTQA/UFPB), Campus I, João Pessoa, $P B$ - CEP: $59.059-900$

${ }^{2}$ Mestranda do Programa de Pós-graduação em Ciência e Tecnologia de Alimentos, PPGCTA/CT/UFPB.
} \\ ${ }^{3}$ Empresa Estadual de Pesquisa Agropecuária da Paraíba - EMEPA. Rua Eurípides Tavares, $n^{\circ}$ 210, Tambiá, João Pessoa, PB- CEP: 58.013-290.
}

\begin{abstract}
RESUMO - Este estudo foi realizado com o objetivo de avaliar os efeitos do sexo e do genótipo sobre a composição centesimal e o perfil de ácidos graxos do músculo Semimembranosus (SM) de ovinos submetidos às mesmas condições de confinamento. Foram utilizados 12 cordeiros, quatro machos inteiros e quatro fêmeas da raça Santa Inês (SI) e quatro machos inteiros mestiços $1 / 2$ Santa Inês x $1 / 2$ Dorper (SI-D). A raça e o sexo não influenciaram a composição centesimal da carne dos cordeiros. No entanto, as concentrações de fósforo e cálcio diferiram significativamente quando considerados estes dois fatores Os ácidos graxos encontrados em maior quantidade na fração lipídica da carne dos animais foram o oléico, o palmítico e o esteárico. Houve efeito do sexo sobre o perfil dos ácidos graxos monoinsaturados na carne dos animais Santa Inês. O perfil de ácidos graxos de mestiços machos SI-D comprovou melhor valor nutricional da carne, pelo maior percentual de ácidos graxos poliinsaturados, pela maior relação AGPI/AGS e pela menor relação w6:w3
\end{abstract}

Palavras-chave: ácidos graxos, Dorper, composição centesimal, raças, Santa Inês, sexo

\section{Effect of genotype and sex on chemical composition and fatty acid profile of sheep meat}

\begin{abstract}
The objective of this study was to investigate the effects of sex and genotype (breed) on the composition and fatty acid profile of the semimembranosus (SM) muscle of feedlot sheep. Four Santa Inês (SI) males, four SI females, and four $1 / 2$ Santa Inês x $1 / 2$ Dorper (SI-D) males were used in this trial. Neither breed nor sex significantly affected the chemical composition of meat. However, the meat contents of phosphorus and calcium were both significantly changed by breed and sex. Oleic, palmitc, and stearic were the fatty acids found in larger amounts in the intramuscular fat of lamb meat in this study There was a significant effect of sex on the profile of unsaturated fatty acids within the SI breed. The fatty acid profile of meat from SI-D sheep showed greater nutritional value because of the highest content of PUFA and PUFA/SFA ratio and the lowest w6:w3 ratio.
\end{abstract}

Key Words: breed, chemical composition, Dorper, fatty acids, lamb, sex, Santa Inez

\section{Introdução}

A exploração de ovinos deslanados encontra-se atualmente bem difundida em todo o Nordeste brasileiro. Ao longo dos anos, os ovinos foram submetidos a um sistema de criação extensivo e, mesmo assim, apresentaram crescimento populacional razoável, atribuído à sua rusticidade e capacidade de adaptação ao clima semi-árido característico das regiões secas (Sousa, 1998).

A raça Santa Inês, desenvolvida no Brasil pelo cruzamento entre as raças Morada Nova e Bergamácia, tem sido apontada como uma alternativa promissora em cruzamentos para produção de cordeiros para abate, por apresentar excelente capacidade de adaptação, além de alta fertilidade e prolificidade (Sousa, 1997). No entanto, em sistemas intensivos, cordeiros Santa Inês têm desempenho e características de carcaças inferiores às raças de corte (Dorper, Suffolk, Ile de France). A utilização de cordeiros de corte e ovelhas Santa Inês pode melhorar o desempenho e as características de carcaça, por possibilitar a geração de crias com maior potencial para ganho de peso, diminuindo o tempo para o abate e os custos de produção.

Dorper é uma raça de ovinos tipo corte originária da África do Sul, resultante do cruzamento das raças "Dorset Horn" e "Blackheaded Persian", sendo caracterizada pela cabeça preta (Dorper) ou branca (White Dorper). A raça foi 
desenvolvida para as regiões extensivas e áridas da África do Sul e destaca-se pela alta fertilidade, pelo rápido ganho de peso, pela excelente conformação de carcaça e pela adaptabilidade às regiões áridas e subtropicais (Sousa \& Leite, 2000). No Brasil, foi introduzida a partir de 1998, por meio do programa de melhoramento genético desenvolvido pela Empresa Estadual de Pesquisa do Estado da Paraíba (EMEPA-PB), que tinha como objetivos a obtenção de melhores resultados zootécnicos e econômicos com ovinos de corte, considerando tratar-se de uma raça precoce selecionada para produção de carne.

A busca por alimentos de qualidade tem aumentado nos últimos anos, tornando necessária a profissionalização nos setores de produção, a industrialização e a comercialização. Os fatores que determinam a qualidade de carnes incluem a composição química, principalmente a quantidade e qualidade dos componentes gordurosos, e as características organolépticas, diretamente ligadas ao sabor ou às qualidades gustativas (Madruga, 2004).

Fatores diversos, como o sexo, a raça, a idade de abate e o peso ao abate, entre outros, podem afetar a qualidade da carne ovina. Sañudo et al. (1997) reportaram que, em geral, as fêmeas de cordeiros depositam mais gordura distribuída nas regiões lombares e ventrais da carcaça em comparação aos machos. Lopez et al. (1991) relataram que, dentro de uma mesma raça, o efeito do sexo sobre a composição tecidual pode acentuar-se com o peso de abate e verificaram que as fêmeas depositaram mais tecido adiposo que os machos. Rosa et al. (2002) também verificaram efeito significativo do sexo sobre a proporção de osso da carcaça de cordeiros, de modo que os machos apresentaram maior proporção de ossos em comparação às fêmeas.

Tem-se observado recentemente grande interesse pela manipulação dos ácidos graxos na composição das carnes em geral. Esse interesse resulta do fato de que a carne é a principal fonte de gordura na dieta, em especial de ácidos graxos saturados, envolvidos em doenças coronárias e câncer, doenças associadas à vida moderna. Além disso, a importância nutricional do perfil dos ácidos graxos para a saúde do homem tem-se justificado pelo fato de que o perfil dos ácidos graxos geralmente tem pouca influência no valor comercial da carcaça em comparação ao conteúdo total de gordura. É importante ressaltar, no entanto, que as propriedades físicas e químicas dos lipídios afetam diretamente as qualidades nutricionais, sensoriais e de conservação da carne: o "flavour" é influenciado pelo perfil dos ácidos graxos (Mottram, 1998; Madruga 2004); as gorduras saturadas solidificam após cozimento, influenciando a palatabilidade da carne; a presença dos ácidos graxos insaturados aumenta o potencial de oxidação, influenciando diretamente a vida-de-prateleira da carne in natura ou cozida.

Apesar da vasta literatura sobre o efeito do sexo na caracterização de carcaças de cordeiros, são poucos os dados sobre o efeito do sexo no perfil de ácidos graxos da carne de cordeiros, em especial da Santa Inês. O objetivo neste trabalho foi avaliar a qualidade química e o perfil de ácidos graxos da carne de cordeiros puros Santa Inês (machos e fêmeas) e mestiços (machos) resultantes do cruzamento de ovelhas Santa Inês com reprodutores Dorper submetidos às mesmas condições de confinamento.

\section{Material e Métodos}

O estudo foi realizado utilizando-se 12 cordeiros, oito da raça nativa Santa Inês (quatro machos inteiros e quatro fêmeas) e quatro machos inteiros mestiços meio-sangue (Santa Inês x Dorper). Todos os animais apresentavam peso vivo inicial de 18 a $20 \mathrm{~kg}$ e quatro meses de idade. Os animais foram submetidos a um período experimental de 90 dias, precedido de 14 dias para adaptação ao manejo e à dieta. Durante o período de confinamento, na Estação Experimental de Pendência, base física pertencente à Empresa Estadual de Pesquisa Agropecuária da Paraíba (EMEPA-PB), os animais foram alojados em gaiolas individuais $(0,80 \times 1,20 \mathrm{~m})$ providas de comedouros e bebedouros, dispostas em um galpão de alvenaria. A dieta, balanceada para atender às exigências nutricionais dos animais, foi constituída de $35 \%$ de feno de maniçoba, $40 \%$ de milho, $24 \%$ de soja e $1 \%$ de mistura de sal mineral, e fornecida ad libitum.

Os cordeiros, na data para o abate, calculada por meio do controle de peso e idade ( 7 meses e peso médio de $90 \mathrm{~kg}$ ), foram submetidos a jejum hídrico de 24 horas e, em seguida, foram abatidos segundo condições recomendadas pelas normas vigentes do RIISPOA. Após o abate, foram resfriadas em câmara frigorífica a $-5^{\circ} \mathrm{C}$ por 24 horas. Em seguida, os músculos Semitendinosus do lado esquerdo da carcaça foram secionados, identificados, embalados em sacos plásticos e armazenados em freezer $\left(-18^{\circ} \mathrm{C}\right)$, por um período não superior a dois meses, até a realização das análises.

Os músculos foram descongelados em geladeira convencional por 24 horas. Seqüencialmente, realizou-se a toalete, com a retirada da gordura de cobertura e a trituração em liquidificador até a obtenção de uma pasta homogênea.

Foram determinados o teor de umidade, por secagem em estufa a $105^{\circ} \mathrm{C}$ até peso constante; o teor de cinzas, por incineração em mufla a $550^{\circ} \mathrm{C}$ até peso constante; e o teor 
de nitrogênio, pelo método semimicro de Kjeldahl, utilizando-se o fator de 6,25 para conversão de nitrogênio total em proteínas. Todos os constituintes foram quantificados segundo metodologia descrita pela AOAC (2000). A gordura foi extraída com clorofórmio e metanol pelo método de Folch et al. (1957).

A partir do resíduo mineral fixo (solução de cinzas), foram dosados os minerais ferro, fósforo e cálcio. A determinação de fósforo total foi feita pelo método colorimétrico (AOAC, 2000), utilizando-se espectrofotômetro UV/visível (Micronal D-220) com comprimento de onda de $650 \mathrm{~nm}$.

A determinação de ferro total foi feita pelo método colorimétrico, descrito por Rangana (1991), em espectrofotômetro UV/visível (Micronal D-220), com comprimento de onda de $480 \mathrm{~nm}$. A determinação de cálcio foi feita pelo método titulométrico (Adolfo Lutz, 1985) utilizando-se EDTA.

A metilação dos ácidos graxos foi realizada segundo metodologia descrita por Hartman \& Lago (1973). A identificação e quantificação dos ésteres de ácidos graxos foram obtidas por meio de análises em cromatógrafo gasoso HP5890 Serie II de alta resolução, acoplado com detector de ionização de chama. A separação ocorreu em coluna capilar de sílica fundida (HP-INNOWax), do tipo polar, empacotada com polietilenoglicol com dimensões: $30 \mathrm{~m}$ x $0,25 \mathrm{~mm}$ e $0,25 \mathrm{~mm}$. As amostras de ésteres metílicos $(1,0 \mu \mathrm{L})$ foram introduzidas em um injetor tipo split/spliless a $230^{\circ} \mathrm{C}$ e os chromatogramas foram registrados em um software tipo Hewlett-Packard HP3365 ChemStation System. As temperaturas iniciais e finais da coluna foram, respectivamente, de 120 e $210^{\circ} \mathrm{C}$, com uma rampa intermediária de $8^{\circ} \mathrm{C} / \mathrm{min}$. A temperatura do detector foi mantida em $250^{\circ} \mathrm{C}$.

Os ácidos graxos foram identificados por meio da comparação dos tempos de retenção dos ésteres metílicos das amostras com os padrões de ésteres metílicos de ácidos graxos idênticos (Merck, USA). Experimentos adicionais utilizando-se uma série de padrões de alcanos, com variação de $\mathrm{C}_{6}$ a $\mathrm{C}_{19}$ sob condições analíticas idênticas, foram realizados para se certificarem os índices de retenção linear dos ácidos graxos e a identidade positiva dos componentes de interesse mediante a comparação dos resultados das amostras aos índices de retenção, utilizando-se a fórmula de cálculo do Índice de Retenção Linear (Madruga et al., 2003). A quantificação relativa dos ácidos graxos foi realizada pela normalização das áreas dos ésteres metílicos. Os resultados dos ácidos graxos foram expressos em percentual de área (\%).

Os dados obtidos foram analisados estatisticamente por meio de análise de variância (ANOVA) pelo programa estatístico Statistical Analysis System (SAS), versão 6.12 (SAS, 1996), em um delineamento inteiramente casualisado, com três tratamentos $\left(T_{1}\right.$ : animais machos da raça Santa Inês, $\mathrm{T}_{2}$ : animais fêmeas da raça Santa Inês, $\mathrm{T}_{3}$ : animais machos mestiços meio-sangue $-1 / 2$ Santa Inês $x 1 / 2$ Dorper) e quatro repetições. A comparação entre as médias foi realizada pelo teste Tukey a $5 \%$ de probabilidade.

\section{Resultados e Discussão}

Os teores de umidade, cinzas, proteínas e lipídios não diferiram $(\mathrm{P}>0,05)$ entre os sexos e os genótipos (Tabela 1$)$. Portanto, o cruzamento Santa Inês x Dorper objetivando o melhoramento das características de carcaça não influenciou a composição centesimal da carne de ovinos, especialmente o teor de gordura. Provavelmente o abate precoce dos animais inibiu a potencialidade genética da raça Dorper, resultando em maior deposição de tecido gorduroso.

Lawrie (1985) reporta que, em geral, animais machos depositam menos gordura intramuscular que fêmeas, o que não foi observado nesta pesquisa, em virtude da pouca

Tabela 1 - Composição química da carne de ovinos Santa Inês machos e fêmeas e de mestiços machos $1 / 2$ Santa Inês x $1 / 2$ Dorper Table 1 - Chemical composition of the meat from males and females Santa Ines and from the crossbred ${ }^{*} 1 / 2$ Santa Ines $\times 1 / 2$ Dorper male $\mathrm{s}$

\begin{tabular}{|c|c|c|c|}
\hline $\begin{array}{l}\text { Componente }{ }^{2} \\
\text { Item }\end{array}$ & $\begin{array}{l}\mathrm{SI}^{1} \text { macho } \\
\text { SI male }\end{array}$ & $\begin{array}{l}\mathrm{SI}^{1} \text { fêmea } \\
\text { SI female }\end{array}$ & $\begin{array}{l}\text { SI-D }^{1} \text { macho } \\
\text { SI-D male }\end{array}$ \\
\hline $\begin{array}{l}\text { Umidade }(\mathrm{g} / 100 \mathrm{~g}) \text { (Moisture, } \mathrm{g} / 100 \mathrm{~g}) \\
\text { Cinzas }(\mathrm{g} / 100 \mathrm{~g}) \text { (Ash, g/100 g) } \\
\text { Proteínas }(\mathrm{g} / 100 \mathrm{~g}) \text { (Total protein, } \mathrm{g} / 100 \mathrm{~g} \text { ) } \\
\text { Lípidos }(\mathrm{g} / 100 \mathrm{~g}) \text { (Fat, g/100 g) }\end{array}$ & $\begin{array}{r}75,03^{\mathrm{Aa}} \pm 0,58^{2} \\
1,10^{\mathrm{Aa}} \pm 0,05 \\
22,12^{\mathrm{Aa}} \pm 0,47 \\
2,86^{\mathrm{Aa}} \pm 0,46\end{array}$ & $\begin{array}{r}75,46^{\mathrm{A}_{ \pm}}+0,50 \\
0,98^{\mathrm{A}} \pm 0,06 \\
20,39^{\mathrm{A}} \pm 0,47 \\
3,24^{\mathrm{A}} \pm 0,23\end{array}$ & $\begin{array}{r}76,03^{\mathrm{a}} \pm 0,32 \\
1,14^{\mathrm{a}} \pm 0,06 \\
20,50^{\mathrm{a}} \pm 1,02 \\
2,00^{\mathrm{a}} \pm 0,64\end{array}$ \\
\hline $\begin{array}{l}\mathrm{P}(\mathrm{mg} / 100 \mathrm{~g}) \\
\mathrm{Fe}(\mathrm{mg} / 100 \mathrm{~g}) \\
\mathrm{Ca}(\mathrm{mg} / 100 \mathrm{~g})\end{array}$ & $\begin{array}{c}203,10^{\mathrm{Aa}_{ \pm}}+10,54 \\
1,49^{\mathrm{A}, \mathrm{a}_{ \pm}}, 51 \\
10,34^{\mathrm{Aa}} \pm 0,11\end{array}$ & $\begin{array}{r}169,95^{\mathrm{B}_{ \pm}} \pm 6,90 \\
1,83^{\mathrm{B}_{ \pm}}+1,78 \\
7,61^{\mathrm{B}_{ \pm}}+91\end{array}$ & $\begin{array}{r}153,77^{\mathrm{b}} \pm 9,06 \\
1,29^{\mathrm{a}} \pm 1,12 \\
7,56^{\mathrm{b}} \pm 0,72\end{array}$ \\
\hline
\end{tabular}

${ }^{1}$ SI - Santa Inês; SI-D - mestiços $1 / 2$ Santa Inês x $1 / 2$ Dorper.

2 Médias seguidas por letras diferentes maiúsculas (sexo) e minúsculas (raças) nas linhas diferem $(P<0,05)$ pelo teste Tukey.

${ }^{1} \mathrm{SI}$ - Santa Ines; SI-D-1/2 Santa Ines $x 1 / 2$ Dorper.

${ }^{2}$ Means with different capital (sex) and small (breed) letters within the same row differ $(P<0.05)$ by Tukey test. 
idade de abate dos cordeiros, confirmando a deposição tardia do tecido gorduroso na carcaça e na carne dos animais. Ressalta-se que estes resultados corroboram as pesquisas de Zapata et al. (2001), que, ao estudar o efeito de diferentes genótipos nativos do Nordeste brasileiro sobre a composição química da carne de cordeiros das raças Somalis Brasileira x $1 / 2$ Crioula (SB-C) e $1 / 2$ Santa Inês x $1 / 2$ Crioula (SI-C), não detectaram diferenças significativas. Horcada et al. (1998), avaliando o efeito do sexo sobre a composição química da carne ovina, também não notaram diferenças quanto aos teores de umidade, cinzas e proteínas (74,0; 1,0 e $20,9 \%$, respectivamente).

Embora não tenham sido registradas diferenças no teor de gordura, maiores proporções foram encontradas na carne das fêmeas SI $(3,24 \%)$ em relação à dos machos SI (2,86\%), o que está de acordo com os relatos de Horcada et al. (1998), que observaram ( $\mathrm{P}>0,05)$, em cordeiros, maiores proporções de gordura na carne das fêmeas $(3,54 \%)$ que na dos machos (3,15\%). Siqueira et al. (2001) verificaram porcentagens de gordura e espessura da gordura de cobertura predominantemente superior $(\mathrm{P}>0,05)$ em cordeiros fêmeas abatidos em diferentes idades.

Os teores de lipídios da carne dos cordeiros machos SI e dos mestiços SI x Dorper ( $\mathrm{Si}$-D) foram aproximados e semelhantes aos obtidos por Zapata et al. (2001), em perna de SB-C (2,39\%) e SI-C (2,01\%), e por Garcia et al. (1995), no músculo Semimembranosus de ovinos $(2,0 \%)$.

Pérez et al. (2002) registraram, na carne de cordeiros Suffolk, em média, $63,58 \%$ de umidade para cordeiros machos e $61,12 \%$ para cordeiros fêmeas; $18,40 \%$ de proteína para machos e $18,18 \%$ para fêmeas; e $1,08 \%$ de cinzas para machos e $1,13 \%$ para fêmeas, semelhantes aos obtidos neste trabalho.

Entre os três minerais pesquisados, apenas a quantidade de ferro não foi significativamente influenciada pela raça e pelo sexo. Os maiores teores de fósforo e cálcio foram encontrados em SI macho $(203,10$ e $10,34 \mathrm{mg} / 100 \mathrm{~g}$, respectivamente), ressaltando-se que a de ferro foi mais abundante em SI fêmea $(18,27 \mathrm{mg} / 100 \mathrm{~g})$. Maior concentração de $\mathrm{P}, \mathrm{Fe}$ e Ca foi detectada na carne dos cordeiros SI machos em comparação à dos SI-D machos. Na literatura pesquisada, não foi encontrada razão para essas variações, uma vez que as concentrações de minerais têm sido reportadas como componentes com poucas variações (Lawrie, 1985; Hedrick et al., 1994).

Os teores de fósforo encontrados por Almeida (1990) para ovinos SRD foram superiores $(190 \mathrm{mg} / 100 \mathrm{~g})$ aos obtidos nesta pesquisa. No entanto, os teores de ferro, com variação de 1,29 a 1,83 mg/100 g, foram bastante próximos aos descritos por Almeida (1990), cuja concentração foi de
$1,62 \mathrm{mg} / 100 \mathrm{~g}$. Quanto à concentração de cálcio, observou-se que concentrações variando de 7,56 a 10,34 mg/100 g assemelham-se aos valores reportados por Hedrick et al. (1994) e Franco (1998) para carne ovina.

No perfil de ácidos graxos da carne de cordeiros, foram identificados dez ácidos graxos saturados, seis ácidos graxos monoinsaturados e três ácidos graxos poliinsaturados. O ácido oléico (C18:1) foi predominante para ambos os parâmetros, sexo e raça. Alta concentração do ácido oléico na composição da gordura intramuscular de ruminantes tem sido reportada na literatura (Enser et al., 1996; Banskalieva et al., 2000; Sañudo et al., 2000).

Embora não tenha sido detectada influência significativa da variável sexo no percentual total de gordura da carne ovina, em decorrência do abate precoce dos animais, um estudo mais detalhado da qualidade da gordura intramuscular mostrou que o teor do principal ácido graxo (C18:1), o qual tem influência direta no teor de colesterol da carne, foi superior $(\mathrm{P}<0,05)$ nos animais SI fêmea em relação ao dos SI machos (32,02\%), conforme apresentado na Tabela 2. Estes resultados confirmam as observações de Banskalieva et al. (2000), em carne caprina, e de Lawrie (1985), em carne bovina, de que as gorduras intramusculares da carne de animais fêmeas tendem a apresentar maior proporção deste ácido em comparação à de animais machos. Lawrie (1985) enfatiza que o efeito de fatores como sexo, espécie, idade, tipo de músculo, entre outros, na composição dos fosfolipídios e de seus ácidos graxos ainda é pouco conhecido. Na literatura pesquisada, não foi encontrada justificativa para a maior deposição de ácido oléico em ruminantes fêmeas, em comparação a machos da mesma raça, embora esta observação seja freqüentemente reportada. Paralelamente, Banskalieva et al. (2000), em revisão, reportaram que diferenças na composição de ácidos graxos entre animais de sexo diferente têm sido inconsistentes, uma vez que o efeito do fator sexo na composição de ácidos graxos tem sido associado muito mais à fração de ácidos graxos do triglicerídeos (neutros) que à dos fosfolipídios.

Outros dois ácidos graxos, o palmítico (19,30 a 20,60\%) e o esteárico ( 15,16 a 18,61\%), também se sobressaíram no perfil lipídico da carne de cordeiros. Segundo Gaili \& Ali (1985), estes três ácidos são responsáveis por aproximadamente $90 \%$ do total de ácidos graxos da carne de ruminantes. Perfil lipídico de carne de ovinos Santa Inês formado por C18:1, C16:0 e C18:0, tem sido reportado por Rosales (2003), Zapata et al. (2001, 2003), Monteiro \& Shimokomaki (1997) e Garcia et al. (1995).

Os resultados comprovaram que o sexo não influenciou significativamente $(\mathrm{P}>0,05)$ as concentrações de ácidos graxos saturados, monoinsaturados e poliinsaturados da 
Tabela 2 - Médias das áreas dos picos de ácidos graxos da carne de ovinos Santa Inês machos e fêmeas e de mestiços machos de $1 / 2$ Santa Inês $\times 1 / 2$ Dorper

Table 2 - $\quad$ Fatty acid profile of meat from male and female Santa Ines and from the crossbred ${ }^{*} 1 / 2$ Santa Ines $x{ }^{1} / 2$ Dorper male

\begin{tabular}{|c|c|c|c|c|}
\hline $\begin{array}{l}\text { Ácido } \text { graxo }^{2} \\
\text { Fatty acid }\end{array}$ & $\begin{array}{c}\text { Nomenclatura } \\
\text { Terminology }\end{array}$ & $\begin{array}{l}\mathrm{SI}^{1} \text { macho } \\
\text { SI Male }\end{array}$ & $\begin{array}{l}\mathrm{SI}^{1} \text { fêmea } \\
\text { SI Female }\end{array}$ & $\begin{array}{l}\text { SI-D }{ }^{1} \text { macho } \\
\text { SI-D Male }\end{array}$ \\
\hline Saturados & & $44,47^{\mathrm{Aa}} \pm 1,79^{*}$ & $43,39^{\mathrm{A}_{ \pm}} 0,82$ & $42,62^{\mathrm{a}} \pm 0,18$ \\
\hline \multicolumn{5}{|l|}{ Saturated } \\
\hline C 6:0 & Ácido capróico (Caproic acid) & $0,21^{\mathrm{Aa}_{ \pm 0}, 06}$ & $0,15^{\mathrm{A}_{ \pm 0}}, 03$ & $0,28^{\mathrm{a}} \pm 0,02$ \\
\hline C $8: 0$ & Ácido caprílico (Capryilic acid) & $0,34^{\mathrm{Aa}} \pm 0,13$ & $0,30^{\mathrm{A}_{ \pm}} 0,11$ & $0,29^{\mathrm{a}} \pm 0,03$ \\
\hline C $10: 0$ & Ácido cáprico (Capric acid) & $0,15^{\mathrm{Aa}} \pm 0,05$ & $0,13^{\mathrm{A}_{ \pm 0}, 04}$ & $0,08^{\mathrm{b}} \pm 0,01$ \\
\hline C $12: 0$ & Ácido láurico (Lauric acid) & $2,17^{\mathrm{Aa}_{ \pm 0}, 57}$ & $1,86^{\mathrm{A}_{ \pm}} 0,56$ & $0,30^{\mathrm{b}} \pm 0,03$ \\
\hline C 14:0 & Ácido mirístico (Myristic acid) & $3,48^{\mathrm{Aa}} \pm 0,64$ & $3,37^{\mathrm{A}_{ \pm 0}, 38}$ & $1,71^{b_{ \pm}} 0,03$ \\
\hline C 15:0 & Ácido pentadecanóico (Pentadecanoic acid) & $0,34^{\mathrm{Aa}} \pm 0,14$ & $0,39^{\mathrm{A}_{ \pm 0}} 03$ & $0,36^{\mathrm{a}} \pm 0,04$ \\
\hline C $16: 0$ & Ácido palmítico (Palmitic acid) & $20,05^{\mathrm{Aa}} \pm 2,27$ & $20,60^{\mathrm{A}_{ \pm 0}, 95}$ & $19,30^{\mathrm{a}} \pm 0,35$ \\
\hline C 17:0 & Ácido margárico (Margaric acid) & $0,84^{\mathrm{Aa}} \pm 0,07$ & $0,86^{\mathrm{A}_{ \pm}} 0,06$ & $0,89^{a} \pm 0,02$ \\
\hline C 18:0 & Ácido esteárico (Stearic acid) & $16,08^{\mathrm{Aa}_{ \pm}} 1,17$ & $15,16^{\mathrm{A}_{ \pm}} 0,20$ & $18,61^{\mathrm{b}} \pm 0,49$ \\
\hline C 20:0 & Ácido araquídico (Arachidic acid) & $0,81^{\mathrm{Aa}} \pm 0,15$ & $0,57^{\mathrm{B}} \pm 0,07$ & $0,81^{\mathrm{a}} \pm 0,03$ \\
\hline Monoinsaturados & & $43,20^{\mathrm{Ab}} \pm 1,68$ & $45,03^{\mathrm{A}_{ \pm}} 0,33$ & $38,76^{\mathrm{a}} \pm 0,43$ \\
\hline \multicolumn{5}{|l|}{ Unsaturated } \\
\hline C $14: 1$ & Ácido miristoléico (Myristoleic acid) & $0,13^{\mathrm{Aa}} \pm 0,02$ & $0,17^{\mathrm{B}} \pm 0,02$ & $0,15^{\mathrm{a}} \pm 0,02$ \\
\hline C $15: 1$ & Ácido pentadecenóico (Pentadecenoic acid) & $2,61^{\mathrm{Aa}} \pm 0,75$ & $2,32^{\mathrm{A}_{ \pm}} 0,28$ & $1,27^{\mathrm{b}} \pm 0,07$ \\
\hline C $16: 1 w 7$ & Ácido palmitoléico (Palmitoleic acid) & $1,59^{\mathrm{Aa}} \pm 0,24$ & $2,18^{\mathrm{B}} \pm 0,30$ & $1,21^{\mathrm{b}} \pm 0,08$ \\
\hline C $17: 1$ & Ácido heptadecenóico (Heptedecenoic acid) & $0,74^{\mathrm{Aa}} \pm 0,22$ & $0,62^{\mathrm{A}_{ \pm}}, 06$ & $0,51^{\mathrm{a}} \pm 0,05$ \\
\hline C $18: 1 w 9$ & Ácido oléico (Oleic acid) & $32,02^{\mathrm{Aa}_{ \pm}, 13}$ & $35,57^{\mathrm{B}} \pm 0,52$ & $30,66^{\mathrm{a}} \pm 0,17$ \\
\hline C 20:1w9 & Ácido gadoléico (Gadoleic acid) & $6,11^{\mathrm{Aa}} \pm 0,68$ & $4,17^{\mathrm{B}} \pm 0,46$ & $4,96^{\mathrm{b}} \pm 0,40$ \\
\hline Poliinsaturado & & $12,33^{\mathrm{Aa}_{ \pm}}, 23$ & $11,57^{\mathrm{A}_{ \pm}} 0,91$ & $18,62^{\mathrm{b}} \pm 0,32$ \\
\hline \multicolumn{5}{|l|}{ Polyunsaturated } \\
\hline C 18:2w6 & Ácido linoléico (Linoleic acid) & $10,75^{\mathrm{Aa}} \pm 1,09$ & $10,24^{\mathrm{A}_{ \pm}} 0,84$ & $17,21^{\mathrm{b}} \pm 0,35$ \\
\hline C $18: 3 w 3$ & Ácido linolênico (Linolenic acid) & $0,99^{\mathrm{Aa}_{ \pm}} 0,20$ & $0,77^{\mathrm{A}} \pm 0,07$ & $0,87^{\mathrm{a}} \pm 0,03$ \\
\hline C $20: 2$ & Ácido eicosadienóico & $0,59^{\mathrm{Aa}} \pm 0,05$ & $0,56^{\mathrm{A}} \pm 0,09$ & $0,54^{\mathrm{a}} \pm 0,03$ \\
\hline AGMI/AGS (MUFA:SFA) & $0,97^{\mathrm{Aa}} \pm 0,07$ & $1,04^{\mathrm{A}_{ \pm}} 0,02$ & $0,91^{\mathrm{a}} \pm 0,01$ & \\
\hline AGPI/AGS (PUFA:SFA) & $0,28^{\mathrm{Aa}} \pm 0,03$ & $0,27^{\mathrm{A}_{ \pm}}, 03$ & $0,44^{\mathrm{b}} \pm 0,01$ & \\
\hline$(\mathrm{C} 18: 0+\mathrm{C} 18: 1): \mathrm{C} 16: 0$ & $2,40^{\mathrm{Aa}_{ \pm 0}, 09}$ & $2,46^{\mathrm{A}_{ \pm}}+0,04$ & $2,55^{\mathrm{a}} \pm 0,01$ & \\
\hline$w 6: w 3$ & $0,09^{\mathrm{Aa}}$ & $0,07^{\mathrm{A}}$ & $0,05^{\mathrm{b}}$ & \\
\hline
\end{tabular}

1 SI - Santa Inês; SI-D - mestiços $1 / 2$ Santa Inês x $1 / 2$ Dorper.

2 Médias seguidas por letras diferentes maiúsculas (sexo) e minúsculas (raças) nas linhas diferem $(P<0,05)$ pelo teste Tukey.

AGS: ácidos graxos saturados; AGMI: ácidos graxos monoinsaturados; AGPI: ácidos graxos poliinsaturados.

1 SI-Santa Ines; SI-D - $1 / 2$ Santa Ines $x 1 / 2$ Dorper.

${ }^{2}$ Means with different capital (sex) and small (breed) letters within the same row differ $(P<0.05)$ by Tukey test.

SFA: saturated fatty acids; MUFA: unsaturadted fatty acids; PUFA: polyunsaturated fatty acids.

carne de ovinos Santa Inês. Vale enfatizar que Lawrie (1985) reportou diferenças nos teores dos ácidos graxos saturados da carne de bovinos machos e fêmeas.

Por outro lado, analisando-se a concentração total dos ácidos graxos insaturados, observou-se que a raça influenciou significativamente as concentrações tanto dos monoinsaturados quanto dos poliinsaturados, sendo que os animais mestiços SI-D apresentaram maior percentual de ácidos graxos poliinsaturados, com alta concentração do ácido linoléico. Estas diferenças provavelmente se justificam pelo fato de ovinos Dorper serem considerados de precocidade de acabamento, tendendo a depositar gordura saturada em idade mais jovem, diminuindo os fosfolipídios da membrana, principalmente quando criados em confinamento (Wood et al., 2003). Diferenças na composição de ácidos graxos de lipídeos de animais de mesma espécie e de diferentes raças têm sido revisadas por Banskalieva et al. (2000) e Wood et al. (2003), sendo atribuídas à influência de fatores diversos, como alimentação, sexo, localização anatômica, idade de abate e peso ao abate.

Wood et al. (2003) reportaram que o Ministério da Saúde do Reino Unido recomenda que a relação AGPI/AGS do perfil lipídico de um alimento deve situar-se acima de 0,4 , para evitar doenças associadas ao consumo de gorduras saturadas. Assim, na relação AGPI/AGS da carne ovina pesquisada, os animais da raça SI diferiram significativamente $(\mathrm{P}<0,05)$ dos mestiços SI-D, com valores de 0,28 e 0,44 respectivamente, demonstrando que o cruzamento Santa Inês x Dorper melhorou o perfil lipídico da carne de cordeiros Santa Inês. A carne de cordeiros SI-D também se sobressaiu significativamente $(\mathrm{P}<0,05)$ na relação $w 6: w 3$, 
a qual apresentou menor valor $(0,05)$ quando comparada à de SI $(0,09)$. Além disso, a carne ovina, nos três grupos, apresentou a relação $w 6: w 3$ bem abaixo do mínimo recomendado, que deve ser inferior a 4 , quando visa eliminar fatores de riscos de doenças como câncer e as doenças coronárias, associados à alimentação (Wood et al., 2003; Banskalieva et al., 2000).

Não houve influencia significativa do fator $\operatorname{sexo}(\mathrm{P}>0,05)$ nas relações AGPI/AGS e w6:w3 da carne de ovinos SI.

Considerando-se que a concentração plasmática de colesterol é influenciada pela composição de ácidos graxos da dieta (Rhee, 1992) e sabendo-se que o ácido graxo oléico (C18:1) diminui o nível de colesterol sanguíneo, enquanto o ácido graxo palmítico (C16:0) aumenta o de colesterol sanguíneo, e que o ácido esteárico (C18:0) não exerce nenhuma influência, é importante analisar o comportamento destes três ácidos na carne ovina. Neste contexto, a carne de cordeiros SI fêmeas, com concentração de C18:1 de 35,57\%, apresentou-se mais saudável que a de SI macho $(32,02 \%)$, pois os percentuais do ácido palmítico não sofreram influência significativa $(\mathrm{P}>0,05)$ dos fatores raça e sexo.

\section{Conclusões}

Nas condições experimentais, os parâmetros raça e sexo não influenciaram a composição centesimal da carne de cordeiro. No entanto, as concentrações de fósforo, ferro e cálcio diferiram significativamente na carne de Santa Inês machos e fêmeas, de modo que, juntamente com os percentuais totais de ácidos graxos mono e poliinsaturados, as concentrações desses minerais foram significativamente influenciadas pelos cruzamentos. Qualitativamente, o perfil de ácidos graxos de mestiços SI-D apresentou melhor valor nutricional, comprovado pela maior concentração de ácidos graxos poliinsaturados e pelas relações maior de AGPI/AGS e menor de $w 6: w 3$.

\section{Agradecimento}

Ao CNPq e à CAPES, pelo apoio financeiro e pelas bolsas concedidas. À EMEPA/PB, pelo fornecimento dos animais em estudo.

\section{Literatura Citada}

ALMEIDA, M.M.M. Estudo da composição química das carnes de caprinos e ovinos criados no sertão do Ceará. Fortaleza: Universidade Federal do Ceará, 1990. 78p. Dissertação (Mestrado em Ciência e Tecnologia de Alimentos) - Universidade Federal do Ceará, 1990.
ASSOCIATION OF OFFICIAL ANALITICAL CHEMISTS - AOAC. Official methods of analysis. 19.ed. Washington, D.C.: 2000. 1219 p.

BANSKALIEVA, V.; SAHLU, T.; GOETSCH, A.L. Fatty acid composition of goat muscles and fat depots - a review. Small Ruminant Research, v.37, p.255-268, 2000.

ENSER, M.; HALLETT, K.; HEWETT, B. et al. Fatty acid content and composition of English beef, lamb and pork at reatil. Meat Science, v.44, p.443-458, 1996.

FOLCH, J.; FESS, M.; SLOANNE STANLEY, G.H. A simple method for isolation and purification of total lipids from animal tissues. The Journal of Biological Chemistry, v.226, n.1, p.497-509, 1957.

FRANCO, G. Tabela de composição centesimal. 12.ed. Rio de Janeiro: Atheneu, 1998. 148p.

GAILI, E.S.; ALI, A.E. Meat from Sudan desert sheep and goats: part 2 - composition of the muscular and fatty tissues. Meat Science, v.13, p.229-236, 1985.

GARCIA, P.T.; CASAL, J.J.; MARGARIA, C.A. et al. Lipids from lamb meat. In: INTERNATIONAL CONGRESS OF MEAT SCIENCE AND TECHNOLOGY, 41., 1995, San Antonio. Proceedings... San Antonio: American Meat Science Association, 1995. v.2, p.56-57.

HARTMAN, L.; LAGO, B.C. Rapid preparation of fatty methyl esters from lipids, Laboratory Practice, v.22, p.475-477, 1973.

HEDRICK, H.B.; ABERLE, E.D.; FORREST, J.C et al. Principles of meat science. 3.ed. Kendall: Hunt Publishing Company, 1994. p. 292-293.

HORCADA, A.; BERIAIN, M.J.; PURROY, A. et al. Effect of sex on meat quality of Spanish lamb breeds (Lacha and Rasa Aragonesa). Animal Science, v.67, p.541-547, 1998.

INSTITUTO ADOLFO LUTZ. Normas analíticas: métodos químicos e físicos para análise de alimentos. São Paulo: Instituto de Tecnologia de Alimentos, 1985. 533p.

LAWRIE, R.A. Meat science. 4.ed. Oxford: Pergamon Press, 1985. $267 \mathrm{p}$.

LOPEZ M.; COLOMER, F.; RODRÍGUEZ, M. Producción de carne en la raza Lacha. I. Rendimento de la canal y componentes del quinto quarto de lechales, ternascos y corderos. In: JORNADAS CIENTÍFICAS DE LA SOCIEDAD ESPANOLA DE OVINOTECNIA Y CAPRINOTECNIA - SEOC, 1991, Pamplona. Resumos... Pamplona: 1991. p.433-441.

MADRUGA, M.S. Qualidade química, sensorial e aromática da carne caprina e ovina: mitos e verdades. In: VIII ENCONTRO NACIONAL PARA O DESENVOLVIMENTO DA ESPÉCIE CAPRINA, 8., 2004, Botucatu. Anais... São Paulo: 2004. p.215-234.

MADRUGA, M.S.; SOUZA, J.G.; ARRUDA, S.G.B. et al. Carne caprina de animais mestiços: estudos do perfil aromático. Ciência e Tecnologia de Alimentos, v.23, n.3, p.323-329, 2003.

MONTEIRO, E.M.; SHIMOKOMAKI, M. Influência da raça no perfil dos ácidos graxos na carne de cordeiros. In: CONGRESSO BRASILEIRO DE CIÊNCIA E TECNOLOGIA DE ALIMENTOS, 16., 1997, Rio de Janeiro. Anais... Rio de Janeiro: Sociedade Brasileira de Ciência e Tecnologia de Alimentos, 1997. v.2, p.1328-1331.

MOTTRAM, D.S. Flavour formation in meat and meat products: a review. Food Chemistry, v.62, n.4, p.415-424, 1998.

PÉREZ, P.; MAINO, M.; TOMIC, G. et al. Carcass characteristics and meat quality of Suffolk Down suckling lambs. Small Ruminant Research, v.44, p.233-240, 2002.

RANGANNA, S. Handbook of analysis and quality control for fruit and vegetables products. New Delhi: McGraw-Hill, 1991. 1112 p.

RHEE, K.S. Fatty acids in meats and meat products. In: CHOW, C.K. (Ed.). Fatty acids in foods and their health implications. New York: Marcel Dekker, 1992. p.65-93.

ROSA, G.T.; PIRES, C.C.; SILVA, J.H.S. et al. Crescimento de osso, músculo e gordura dos cortes da carcaça de cordeiros e cordeiras 
em diferentes métodos de alimentação. Revista Brasileira Zootecnia, v.31, n.6, p.2283-2289, 2002.

ROSALES, M.D. Influência da alimentação na qualidade de carne de ovinos Santa Inês. João Pessoa: Universidade Federal da Paraíba, 2003. 69p. Dissertação (Mestrado em Ciência e Tecnologia de Alimentos) - Universidade Federal da Paraíba, 2003.

SAÑUDO, C.; ENSER, M.; CAMPO, M.M. et al. Fatty acid composition and fatty acid characteristics of lamb carcass from Britain and Spain. Meat Science, v.54, p.339-346, 2000.

SAÑUDO, C.; CAMPO, M.M.; SIERRA, I. et al. Breed effect on carcasses and meat quality of suckling lambs. Meat Science, v.46, n.4, p.357-365, 1997.

STATISTICAL ANALYSIS SYSTEM - SAS. User's guide to statistics. Versão 6.12. Cary: North Carolina State University, 1996. 956p.

SIQUEIRA, E.R.; SIMÕES, C.D.; FERNANDES, S. Efeito do sexo e do peso de abate sobre a produção de carne de cordeiro. II. Morfometria da carcaça, pesos dos cortes, composição tecidual e componentes não constituintes da carcaça. Revista Brasileira de Zootecnia, v.30, n.4, p.1299-1307, 2001.

SOUSA, J.G. Aplicação de modelos lineares e não lineares em características de reprodução, sobrevivência e crescimento de ovinos deslanados Santa Inês. Belo Horizonte: Universidade Federal de Minas Gerais, 1997. 139p. Tese (Doutorado em Medicina Veterinária) - Universidade Federal de Minas Gerais, 1997.
SOUSA, W.H. Ovinos Santa Inês: potencialidades e limitações. In: SIMPÓSIO NACIONAL DE MELHORAMENTO ANIMAL, 2., Uberaba, 1998. Anais... Viçosa, MG: Sociedade Brasileira de Melhoramento Animal, 1998. p.233-237.

SOUSA, W.H.; LEITE, P.R.M. Ovinos de corte: a raça Dorper. João Pessoa: Emepa, 2000. 75p.

WOOD, J.D.; RICHARDSON, G.R.; FISHER, A.V. et al. Effects of fatty acids on meat quality; a review. Meat Science, v.66, p.21-32, 2003.

ZAPATA, J.F.F.; NOGUEIRA C.M.; SEABRA, L.M.J. et al. Composições centesimal e lipídica da carne de ovinos do Nordeste brasileiro. Ciência Rural, v.31, n.4, p.691-695, 2001.

ZAPATA, J.F.F.; NOGUEIRA, C.M.; SEABRA, L.M.J. et al. Características da carne de pequenos ruminantes do nordeste do Brasil. Boletim do SBCTA, v.37, n.2, p.146-153, 2003. 